\title{
Cortical Synaptic Arrangements of the Third Visual Pathway in Three Primate Species: Macaca mulatta, Saimiri sciureus, and Aotus trivirgatus
}

\author{
Yuri Shostak, ${ }^{1}$ Yuchuan Ding, ${ }^{1}$ Julia Mavity-Hudson, ${ }^{1}$ and Vivien A. Casagrande ${ }^{1,2,3}$ \\ Departments of ${ }^{1} \mathrm{Cell}$ Biology, ${ }^{2}$ Psychology, and ${ }^{3}$ Ophthalmology and Visual Sciences, Vanderbilt University, Nashville, \\ Tennessee 37232-2175
}

The koniocellular $(K)$ pathway is one of three pathways from the lateral geniculate nucleus (LGN) to primate visual cortex (V1). K pathway projections to the cytochrome oxidase (CO) blobs of V1 suggest involvement in chromatic processing given reports that the $\mathrm{CO}$ blobs in diurnal primates contain cells selective for color. K LGN layers and CO blobs, however, are also well developed in nocturnal primates such as owl monkeys, which are likely to be color blind. Thus, the K pathway plays either different roles in different species or some as yet unidentified common role(s). Because synaptic arrangements underlie functional mechanisms, the purpose of this investigation was to compare the synaptic circuitry related to the $\mathrm{K}$ pathway within the CO blobs of two diurnal primates (macaque monkeys and squirrel monkeys) and one nocturnal primate (owl monkey). Presynaptic $\mathrm{K}$ axons were labeled with wheat germ agglutinin$\mathrm{HRP}$, and presynaptic and postsynaptic profiles in $\mathrm{CO}$ blobs were identified with post-embedding immunocytochemistry for GABA and glutamate. In all three species, $\mathrm{K}$ axon terminals are glutamatergic and larger than local axon terminals, suggesting that they have a greater impact on postsynaptic $\mathrm{CO}$ blob targets than signals arriving via layer IV from the $\mathrm{P}$ or $\mathrm{M}$ pathways. A greater proportion of $\mathrm{K}$ axons, however, synapse with larger glutamatergic shafts in the diurnal monkeys than in the nocturnal owl monkey, perhaps reflecting the importance of color within the K pathway of these diurnal species. Alternatively, the loss of color vision in the owl monkey could impact $\mathrm{K}$ pathway circuitry earlier in the pathway. The basic similarities between $\mathrm{K}$ axon circuitry within the $\mathrm{CO}$ blobs of the three primate species examined also could indicate that this pathway plays some common role or roles across species.

Key words: CO blobs; striate cortex; koniocellular; magnocellular; parvocellular; electron microscopy
A neurochemically distinct population of koniocellular $(\mathrm{K})$ neurons makes up a third channel in the primate lateral geniculate nucleus (LGN). This pathway has been proposed to function in various sensory as well as modulatory roles (for review, see Casagrande, 1994, 1999; Hendry and Reid, 2000). Although it is still unclear exactly what this pathway contributes to vision, a number of lines of evidence suggest the involvement of the $\mathrm{K}$ pathway in color vision. In particular, it has been shown that some $\mathrm{K}$ LGN cells in marmosets and macaque monkeys respond to the onset of a blue stimulus (blue ON cells) (Martin et al., 1997; Reid et al., 1997; White et al., 1998). Moreover, the K pathway is the only one of the three LGN pathways [koniocellular (K), magnocellular (M), and parvocellular $(\mathrm{P})$ ] that directly terminates within the cytochrome oxidase (CO)-rich blobs of layer III of visual cortex (V1) (Livingstone and Hubel, 1982; Lachica and Casagrande, 1992; Ding and Casagrande, 1995, 1997). Evidence exists that the $\mathrm{CO}$ blobs in diurnal macaque monkeys contain a

\footnotetext{
Received Aug. 16, 2001; revised Jan. 2, 2002; accepted Jan. 9, 2002.

This research was supported by National Institutes of Health Grant EY01778 (V.A.C.) and core Grants EY08126 and HD15052. We are especially grateful to Mary Feurtado for her excellent assistance with animal care and anesthesia and to Dr. Gyula Sáry for expert assistance in surgery. We also thank Dr. Jeffrey Schall, Dr. Jon Kaas, Dr. Amy Wiencken-Barger, Jennifer Ichida, Xiangmin Xu, Zhuang Song, and David Royal for helpful comments on this manuscript.

Correspondence should be addressed to Dr. Vivien A. Casagrande, Department of Cell Biology, Vanderbilt University Medical School, Medical Center North C-2310, Nashville, TN 372327-2175. E-mail: vivien.casagrande@mcmail.vanderbilt.edu.

Y. Ding's present address: Department of Neurological Surgery, Wayne State University Medical School, University Health Center, 4201 St. Antonine 6E, Detroit, MI 48201.

Copyright (C) 2002 Society for Neuroscience $\quad 0270-6474 / 02 / 222885-09 \$ 15.00 / 0$
}

high proportion of cells selective for color [however, see Thompson et al., (1979); Livingstone and Hubel (1984); Ts'o and Gilbert (1988); Lennie et al. (1990)]. This information, combined with recent proposals that midget ganglion cells (retinal input to $\mathrm{P}$ LGN cells) may not carry color signals (Calkins and Sterling, 1999) and that K LGN cells could carry all of the color information, has raised major questions concerning the generality of $\mathrm{K}$ pathway function across primates. The problem is that K LGN cells and $\mathrm{CO}$ blobs are as numerous and prominent in nocturnal primates, such as bush babies and owl monkeys, as they are in diurnal primates (Condo and Casagrande, 1990; Casagrande, 1994; Xu et al., 2001). Bush babies and owl monkeys have only a single mid-wavelength (M) cone and no long (L) and short (S) wavelength (i.e., blue) cones (Wikler and Rakic, 1990; Jacobs et al., 1993). In fact, it is highly likely that both bush babies and owl monkeys are color blind (G. H. Jacobs, personal communication) and use their single cones simply to extend their dynamic visual range. These facts raise questions about the functional generality of the K pathway across species. If K LGN cells provide a unique conduit for color signals in diurnal primates, what are they doing in nocturnal primates? Available data suggest that connections and neurochemistry of the K pathway are quite similar in diurnal and nocturnal primates (for review, see Casagrande, 1994). Perhaps the $\mathrm{K}$ pathway simply does different things in diurnal and nocturnal primates. Alternatively, the K pathway may play a more general role in all primates that remains to be identified. The purpose of this study was to investigate the resemblance and differences in the synaptic circuitry related to the $\mathrm{K}$ pathway within the CO blobs of two diurnal primates (the Old World 


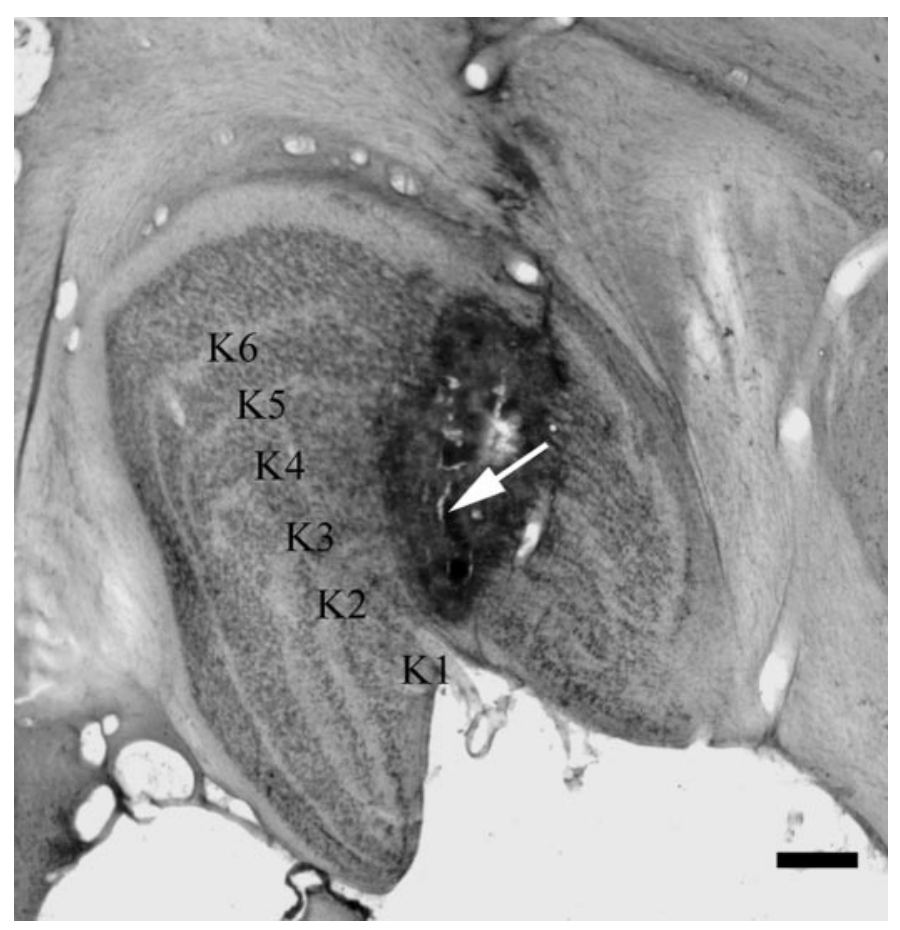

Figure 1. Injection site within the macaque LGN. Note that the tip of the pipette (indicated by an arrow) is placed within K3 but that all LGN layers are labeled in one portion of the LGN. K layers are indicated as $K 1, K 2$, $K 3, K 4, K 5$, and $K 6$. Scale bar, $1 \mathrm{~mm}$.

macaque monkeys and the New World squirrel monkeys) and a nocturnal primate (the New World owl monkeys).

\section{MATERIALS AND METHODS}

Animals. For this study we used two adult squirrel monkeys (Saimiri sciureus), two adult macaque monkeys (Macaca mulatta), and four adult owl monkeys (Aotus trivirgatus). All of the animals were cared for according to the National Institutes of Health Guide for the Care and Use of Laboratory Animals and the guidelines of the Vanderbilt University Animal Care Committee.

$K$ axon labeling. Details of the surgery are similar to those described earlier (Lachica and Casagrande, 1992; Lachica et al., 1993; Ding and Casagrande, 1997, 1998). Briefly, before surgery, atropine sulfate (0.1 $\mathrm{mg} / \mathrm{kg}$ ) was given to inhibit salivation. To inject tracer into the LGN K layers, monkeys were deeply anesthetized with isofluorane (3-4\%) in oxygen and maintained with the same gas mixture at $1-2 \%$ during the surgery. All procedures were performed under aseptic conditions while the animals were deeply anesthetized. Heart and respiration rates were monitored continuously, and reflexes were tested periodically; animals were kept warm with a water-circulating heating pad throughout surgery. Once deeply anesthetized, the monkeys were secured in a stereotaxic apparatus, the skull was exposed, a craniotomy was performed, and a dural flap was elevated. For identification of LGN layers, responses evoked by a flashing light were recorded extracellularly through a tung- sten electrode (5 M $\Omega$; FHC Inc., Bowdoinham, ME). When the K3 layer of LGN was identified on the basis of changes in eye dominance, the electrode was removed and a glass pipette (20-30 $\mu \mathrm{m}$ inner tip diameter) filled with $1 \%$ wheat germ agglutinin conjugated to horseradish peroxidase (WGA-HRP) in saline was inserted at the same location. Recordings then were made to verify the LGN laminar position of the pipette for centering the injections within the K3 layer. Next, WGA-HRP $(\sim 4 \mu \mathrm{l})$ was pressure injected slowly over $8 \mathrm{~min}$. Each injection was large enough to cover all LGN layers within zones approximately one-third to one-half the volume of the LGN. Figure 1 shows an example of one of our injections made in macaque monkey LGN. When the injection was complete, the pipette was removed, the dural flap was repositioned, and the skin was sutured.

After the operation, all animals were given $0.01 \mathrm{mg} / \mathrm{kg}$ of buprenorphin as analgesic and $300,000 \mathrm{U} / \mathrm{kg}$ of long-acting penicillin (Flocillin) and monitored carefully until they were fully conscious and capable of eating and drinking on their own. At that point, animals were returned to their home cages and provided with soft palatable foods and water.

Histological procedures. After a $2 \mathrm{~d}$ survival period, the animals were deeply anesthetized with an overdose of Nembutal. The animals were initially perfused transcardially with a brief rinse of oxygenated saline, then perfused with $2.0 \%$ paraformaldehyde $/ 1.5 \%$ glutaraldehyde in $0.1 \mathrm{M}$ phosphate buffer, $\mathrm{pH} 7.4$, at $4^{\circ} \mathrm{C}$, and finally with the same fixative containing $4.0 \%$ sucrose. Total duration of the perfusion was $\sim 15 \mathrm{~min}$. The brains were removed and post-fixed in $4.0 \%$ sucrose in the fixative at $4^{\circ} \mathrm{C}$ for $1 \mathrm{hr}$. They were then rinsed three times in $0.1 \mathrm{M}$ phosphate buffer, $\mathrm{pH} 7.4$, and placed in $4.0 \%$ sucrose in the same buffer at $4^{\circ} \mathrm{C}$ overnight. The following day, visual cortex was blocked anterior to V2 and dissected from the remainder of the cortical hemisphere. Then, parasagittal $80 \mu \mathrm{m}$ sections were cut on a vibratome. The thalamus was removed, frozen, and sectioned parasagittally at $52 \mu \mathrm{m}$ on a freezing microtome.

WGA-HRP histochemistry. All cortical and LGN sections were treated with a modified tetramethyl benzidine (TMB) and stabilization procedure (Mesulam, 1978; Horn and Hoffman, 1987). Sections to be used for light microscopy were then mounted on gelatin-coated slides, air dried, defatted, dipped briefly in a clearing agent (Histo-Clear), and coverslipped. Counterstaining was unnecessary in these cases because LGN and cortical layers were clearly visible in the TMB-treated sections. All LGN injection sites were reconstructed from serial sections using a microprojector at low magnification $(170 \times)$ to document the location and extent of the WGA-HRP label.

Electron microscopic post-embedding immunocytochemistry. All cortical sections were post-fixed with $1.0 \%$ osmium tetroxide in $0.1 \mathrm{M}$ phosphate buffer at $4^{\circ} \mathrm{C}$ and stained en bloc with uranyl acetate $(2.0 \%$ solution in $70 \%$ ethanol, for $1 \mathrm{hr}$ at $4^{\circ} \mathrm{C}$ ), subsequently dehydrated in an ascending series of graded ethanols, and embedded in Epon resin overnight. After polymerization at $60^{\circ} \mathrm{C}$ for $2 \mathrm{~d}$ and before ultrathin sectioning, slices containing WGA-HRP-labeled $\mathrm{K}$ axons in cortical layer IIIB were dissected from the remainder of the tissue with a NeuroPunch (Ted Pella, Redding, CA). The neuropunches were selected from cortical regions with the most intense label. Within these cortical areas, clear axonal label was evident within layers VI, both halves of layer IVC, IVA, and IIIB blobs, and layer I, demonstrating that all P, M, and K LGN layers were involved in the injection. The neuropunches were centered on the patches of WGA-HRP label within layer IIIB. Because K axons terminate as patches that colocalize with the $\mathrm{CO}$ blobs in all species that have been examined, including macaque monkey (Livingstone and Hubel, 1982; Fitzpatrick et al., 1983; Lachica and Casagrande, 1992; Casagrande et al., 1997; Ding and Casagrande, 1997, 1998), we made the assumption in this study that the patches of label visualized within layer IIIB of V1

Table 1. Postsynaptic targets of $\mathrm{K}$ axon terminals

Postsynaptic targets

\begin{tabular}{|c|c|c|c|c|c|}
\hline \multirow[b]{3}{*}{ Species } & \multirow[b]{3}{*}{$\mathrm{K}$ terminals } & \\
\hline & & \multicolumn{2}{|l|}{ Dendritic shafts } & \multicolumn{2}{|l|}{ Spines } \\
\hline & & Glutamatergic & GABAergic & Glutamatergic & No label \\
\hline Owl monkey & $n=46$ & $n=11$ & $n=3$ & $n=33$ & $n=4$ \\
\hline Squirrel monkey & $n=66$ & $n=21$ & $n=9$ & $n=31$ & $n=5$ \\
\hline Macaque monkey & $n=53$ & $n=18$ & $n=3$ & $n=29$ & $n=3$ \\
\hline
\end{tabular}

Total CO blob area examined: squirrel monkey $=1805.76 \mu \mathrm{m}^{2}$; owl monkey $=1787.52 \mu \mathrm{m}^{2}$; macaque monkey $=1696.32 \mu \mathrm{m}^{2}$. The mismatch between the numbers of $\mathrm{K}$ terminals and their postsynaptic targets reflects the fact that some $\mathrm{K}$ axons make contact with more than one postsynaptic target. $n$ expresses the total number of the profiles. 

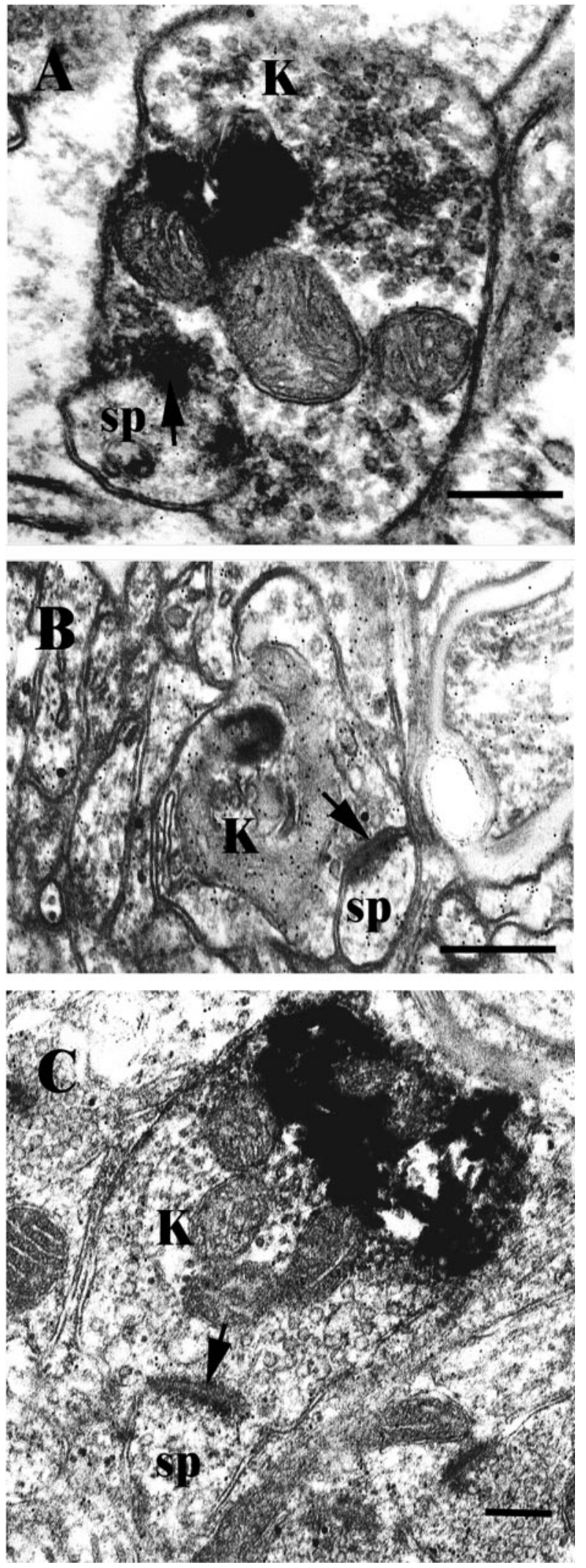

Figure 2. K axons $(K)$, identified by black diff use electron-dense reaction product, mainly make single asymmetric synaptic contacts (examples are indicated by arrows) with glutamatergic dendritic spines ( $s p$ ). Small gold particles $(10 \mathrm{~nm})$ showing immunoreactivity for glutamate are seen as small black dots. $A$, Squirrel monkey; $B$, macaque monkey; $C$, owl monkey. Scale bar, $0.5 \mu \mathrm{m}$.

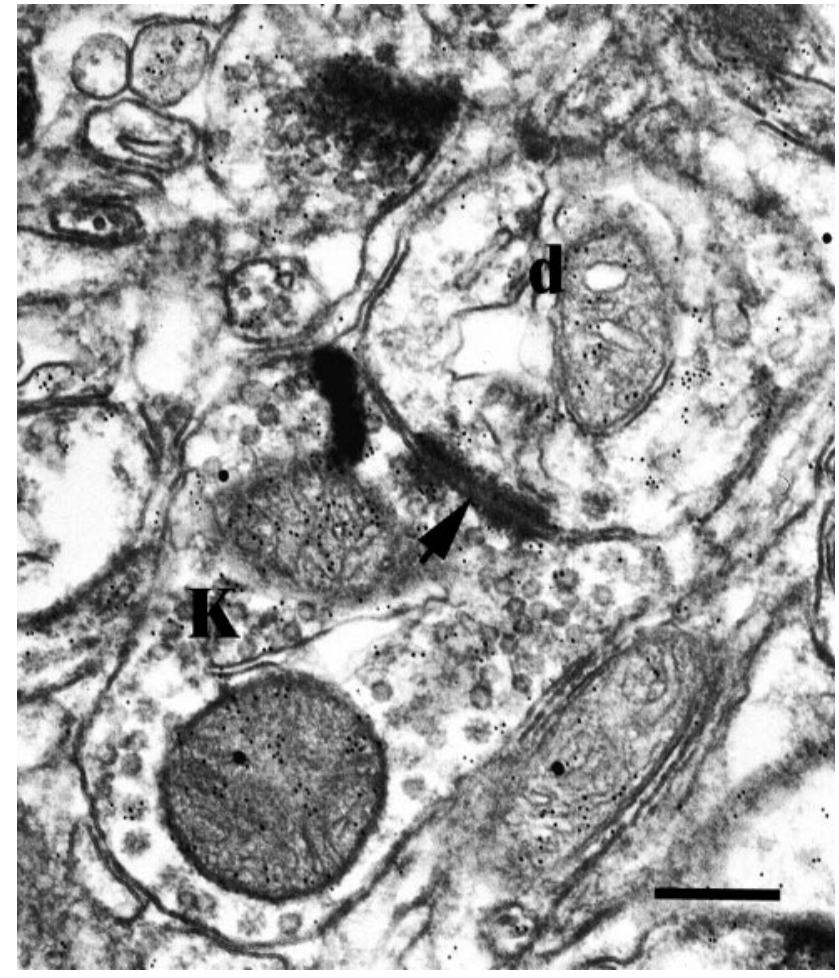

Figure 3. Squirrel monkey. A WGA-HRP-labeled K axon ( $K)$, identified by black diffuse electron-dense reaction product, makes an asymmetric perforated synapse (arrow) onto a glutamatergic dendritic shaft $(d)$. Small gold particles $(10 \mathrm{~nm})$ showing immunoreactivity for glutamate are seen as small black dots. Scale bar, $0.5 \mu \mathrm{m}$.

originated from $\mathrm{K}$ axons. A small portion of cortical layers IIIA and IIIC was included within these punches but was removed later when the block was trimmed before ultrathin sectioning. Ultrathin sections $(\sim 70 \mathrm{~nm})$ were cut with a diamond knife using an Ultracut $\mathrm{E}(\mathrm{AO} /$ Reichert $)$ and collected on uncoated 200-mesh nickel grids (EM Sciences, Washington, PA).

A modification of the technique originally described by Phend et al (1992) was used in this study to optimize post-embedding double immunocytochemistry for glutamate and GABA. Briefly, ultrathin sections on grids were rinsed for $5 \mathrm{~min}$ in TBST $(0.9 \% \mathrm{NaCl}, 0.1 \%$ Triton X-100 in $0.05 \mathrm{M}$ Tris, $\mathrm{pH}$ 7.6) and then incubated overnight with anti-glutamate primary antibody (rabbit polyclonal; Chemicon International, Temecula CA) diluted 1:50 in TBST. After rinsing in TBST, $\mathrm{pH}$ 7.6, and TBST, $\mathrm{pH}$ 8.2 , sections were incubated in secondary goat anti-rabbit antibody conjugated to $10 \mathrm{~nm}$ gold (Ted Pella) diluted 1:20 in TBST, $\mathrm{pH} \mathrm{8.2,} \mathrm{for} 1 \mathrm{hr}$. After completion of the glutamate immunostaining, the binding sites were deactivated by exposure to paraformaldehyde vapors in an $80^{\circ} \mathrm{C}$ oven for $1 \mathrm{hr}$. Sections were then incubated with anti-GABA antibody (rabbit polyclonal; Sigma, St. Louis, MO) diluted 1:2000 in TBST, pH 7.6, for $24 \mathrm{hr}$, followed by incubation in a goat anti-rabbit IgG conjugated to $30 \mathrm{~nm}$ gold (Ted Pella) diluted 1:20 for $1 \mathrm{hr}$. After washing in deionized water, the sections were counterstained with uranyl acetate and lead citrate (Reynolds, 1963) and examined using a Hitachi H-800 transmission electron microscope with an acceleration voltage of $100 \mathrm{kV}$. As controls, sections were incubated in solutions omitting each step from the regular staining sequence, keeping the rest of the procedure the same as described above. Sections processed in this way were totally devoid of gold particles. Controls were also done to determine denaturation of free anti-IgG binding sites for the first secondary antibody (goat anti-rabbit IgG conjugated to $10 \mathrm{~nm}$ gold). The efficacy of the latter deactivation was almost $100 \%$

Data collection and analysis. All labeled K axon terminals (WGA-HRP positive) making synaptic contact were analyzed from all three species in at least four to five different punches (i.e., separate blocks) with 10 sections for each punch. Different punches were taken from different CO blobs. Terminal labeling and synapse identification were confirmed by examining at least two adjacent sections. All labeled terminals were photographed at $20,000 \times$. The total $\mathrm{CO}$ blob area examined for all three 
species of monkey was the same (for squirrel monkeys, $1805.76 \mu \mathrm{m}^{2}$; for owl monkeys, $1787.52 \mu \mathrm{m}^{2}$; for macaque monkeys, $1696.32 \mu \mathrm{m}^{2}$ ). Typically, glutamatergic profiles contain only small gold particles, and GABAergic profiles contain only big gold particles with a few small gold particles, indicative of glutamate as a precursor in GABAergic cells. Presynaptic and postsynaptic profiles were considered immunoreactive for glutamate if the ratio of big $(30 \mathrm{~nm})$ to small $(10 \mathrm{~nm})$ gold particles was $<0.0057 / 1 \mu \mathrm{m}^{2}$ and immunoreactive for GABA if the ratio was $>1.047 / 1 \mu \mathrm{m}^{2}(p=0.013 ; t$ test $)$. The above-mentioned ratios for glutamate and GABA were estimated on photographs taken from five morphologically distinctive glutamatergic and GABAergic cells. The total area of dendrites and synapses from these cells was measured, and the total numbers of big and small particles in that area were counted to obtain the gold ratios per $1.0 \mu \mathrm{m}^{2}$ of profile area for glutamatergic and GABAergic cells.

In the present study, we used the criteria proposed originally by Freund et al. (1989) to distinguish dendritic spines from shafts. According to their criteria, all dendritic profiles that contain mitochondria and microtubules were classified as dendritic shafts regardless of their diameter, and all profiles lacking mitochondria and microtubules were classified as dendritic spines.

On the basis of the ultrastructural "size principle" proposed by Pierce and Mendell (1993), in which morphological features associated with synaptic release scale directly in proportion to terminal size, the crosssectional areas of all labeled terminals and postsynaptic dendritic shafts, in which both presynaptic and postsynaptic profiles were distinct, were measured by tracing the contour of the profiles using the BioQuant-IV image analysis system (R\&M Biometric, Nashville, TN). We compared both $\mathrm{K}$ axon terminal sizes with all other axon terminal sizes within the local area and dendritic shafts postsynaptic to $\mathrm{K}$ axons with those postsynaptic to all local axons. The size of the local area was $27.36 \mu \mathrm{m}^{2}$ for all measurements. Results were analyzed using a Student $t$ test for comparisons of two groups and an ANOVA with a post hoc $t$ test for comparison of three or more groups ( $p \leq 0.05$ was considered significant). No efforts were made to quantitatively compare data across the three species of monkeys because of variation in the overall size of processes and differences in the shrinkage coefficient for each species of monkey.

\section{RESULTS}

Both similarities and differences in the synaptic arrangements of $\mathrm{K}$ axons were found across the three primate species. In all three species, $\mathrm{K}$ axon terminals contain glutamate, are larger than the local population of axon terminals, and contact mainly spines; a significant minority also contact glutamatergic dendritic shafts. Approximately $15 \%$ of $\mathrm{K}$ axons synapse on GABAergic dendrites. The most intriguing differences between the two diurnal monkeys and the one nocturnal monkey were the following: in the macaque and squirrel monkeys, a greater percentage of $\mathrm{K}$ axons terminated on dendritic shafts than in the owl monkey, and the glutamatergic dendritic shafts postsynaptic to $\mathrm{K}$ axons were significantly larger than the glutamatergic dendritic shafts postsynaptic to the local population of axons only in the diurnal monkeys. These results are discussed in more detail below.

\section{Similarities between species}

A total of 165 WGA-HRP-labeled K axon terminal profiles were identified (46 from owl monkeys, 66 from squirrel monkeys, and 53 from macaque monkeys) (Table 1 ) by the presence of electrondense reaction product. These geniculocortical $\mathrm{K}$ terminals, containing one to several mitochondria, were loosely packed with clear round vesicles (Fig. 2) and were all immunopositive only for glutamate, as identified by the presence of an appropriate number of small $(10 \mathrm{~nm})$ gold particles (Figs. 2-7) and the absence of large $(30 \mathrm{~nm})$ gold particles. These $\mathrm{K}$ axon terminals were exclusively presynaptic and usually formed small, single, asymmetric synaptic contacts with dendritic profiles, both spines (Fig. 2) and shafts (Fig. 3), but not with cell bodies or other axons.

Using the criteria described by Freund and colleagues (1989),

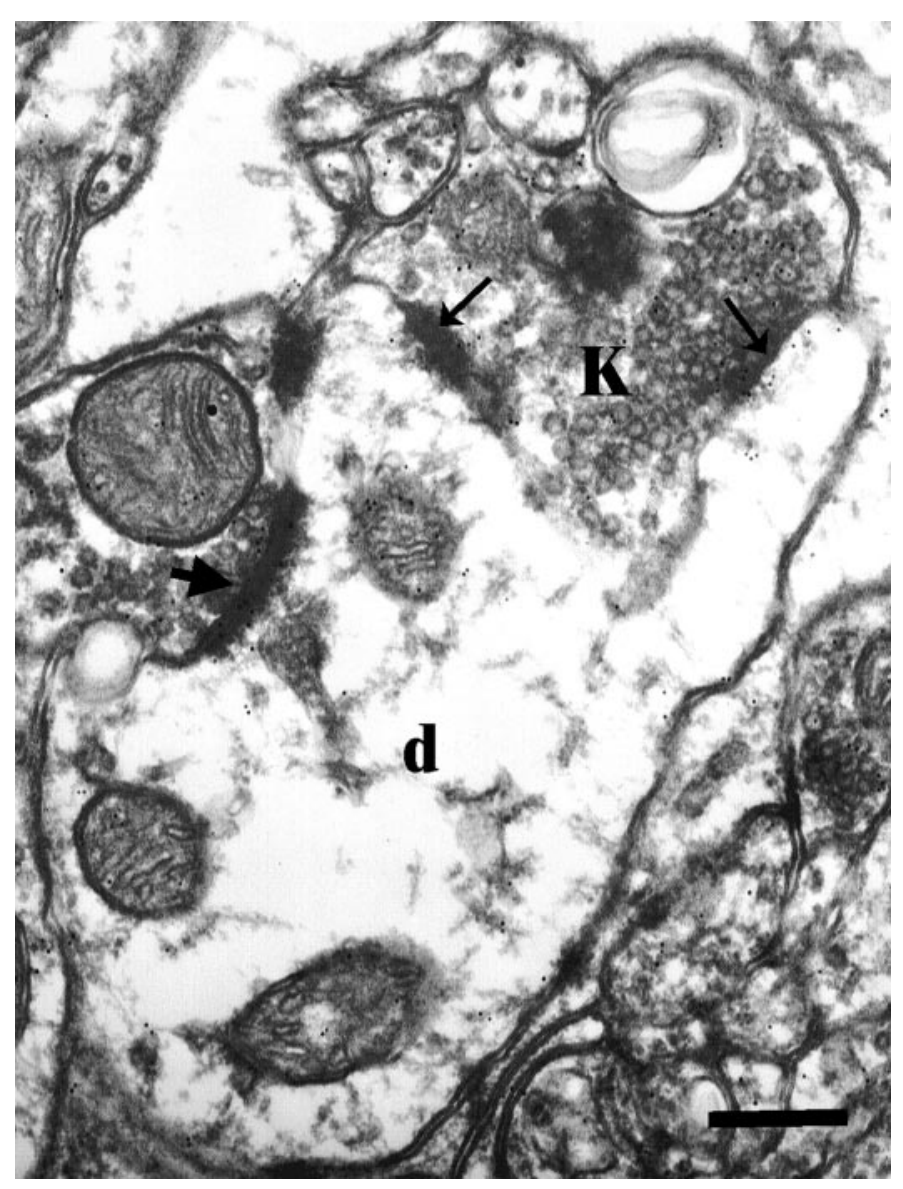

Figure 4. Macaque monkey. A K axon $(K)$, identified by electron-dense WGA-HRP reaction product, makes two synaptic contacts (thin arrows) with one glutamatergic dendritic shaft $(d)$. The dendritic shaft receives another synaptic contact (thick arrow) from an unlabeled axon terminal. Note that the target for the $\mathrm{K}$ terminal here might be interpreted as the shaft and spine portions of a single dendrite. Scale bar, $0.5 \mu \mathrm{m}$.

we determined that most of the $\mathrm{K}$ axons in all three species of monkeys (80.4\% in owl monkey, $54.6 \%$ in squirrel monkey, and $60.4 \%$ in macaque monkey) terminate on dendritic spines (Fig. 2), with the remainder terminating on dendritic shafts (Figs. 3, 4, Table 1).

On the basis of single section analysis, $\mathrm{K}$ axons tend to be involved in simple synaptic relationships with either one dendritic spine or one dendritic shaft. All of the dendritic spines receiving synaptic input from a labeled $\mathrm{K}$ terminal appear to get exclusive input from that terminal. However, a number of larger dendritic shafts that receive synaptic input from $\mathrm{K}$ axons also receive synaptic input from identified GABAergic axons (see Fig. 6), identified glutamatergic axons, and other axonal sources that were not clearly labeled for either glutamate or GABA (Figs. 4, 7). Occasionally, $K$ axons make two synaptic contacts with the same dendritic shaft (Fig. 4). K axons can also exhibit perforated synapses (Fig. 3) with dendritic shafts (Nieto-Sampedro et al., 1982).

As shown in Table 1, most of the postsynaptic targets for $\mathrm{K}$ axons in all three species of monkeys were immunoreactive for glutamate ( $86.3 \%$ for owl monkey, $77.6 \%$ for squirrel monkey, and $88.7 \%$ for macaque monkey); a minority were positive for $\operatorname{GABA}(5.8,15$, and $5.6 \%$, respectively), and the remainder of the postsynaptic targets were unlabeled. Examples of postsynaptic 


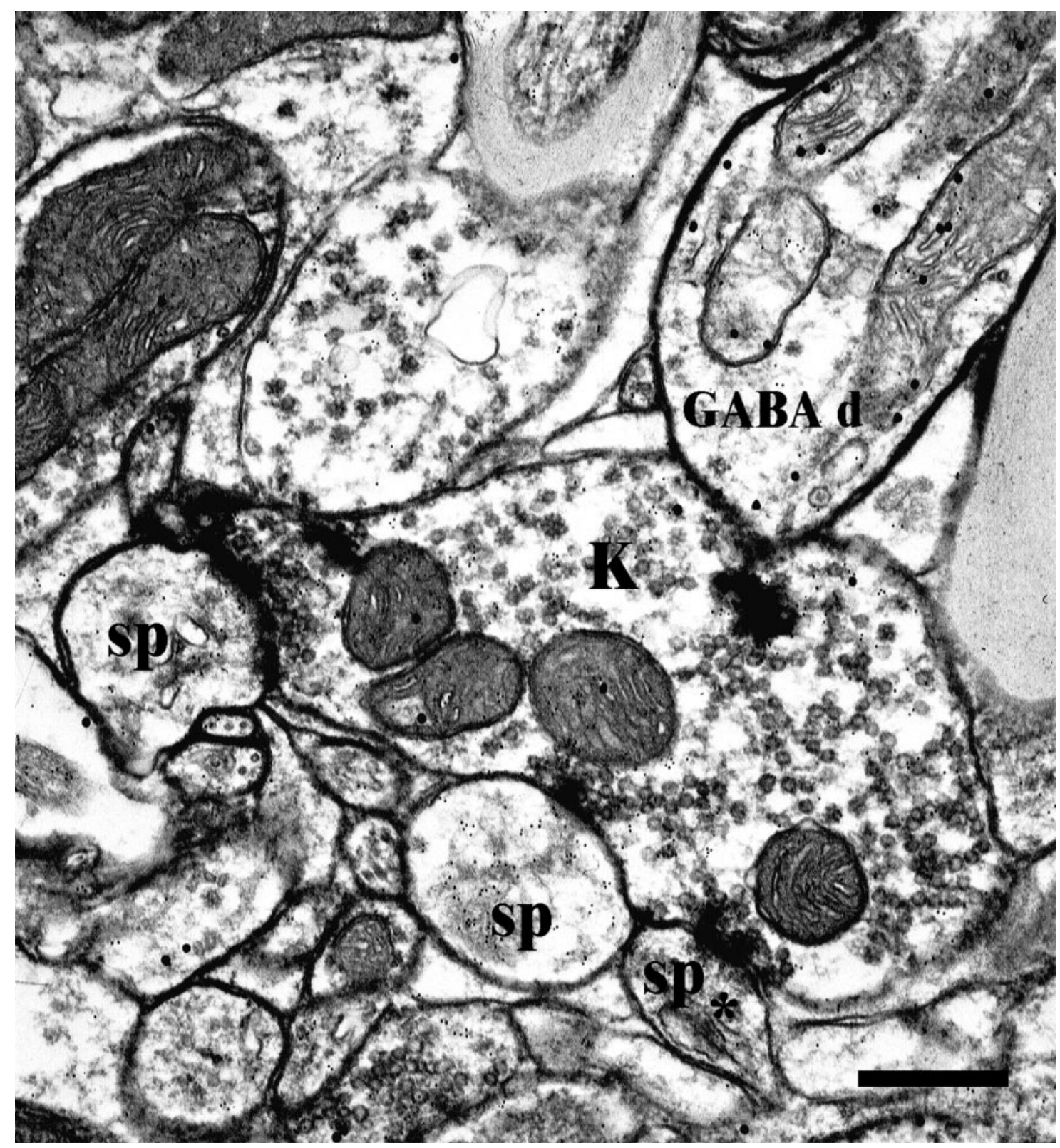

Figure 5. Squirrel monkey. A K axon $(K)$ makes three synaptic contacts with spines $(s p)$; one of them is a perforated synapse. In this case, two spines were identified as glutamatergic on the basis of the presence of small gold particles, and one was unlabeled (asterisk). This K axon likely makes another synaptic contact with the GABAergic (note large gold particles) dendritic shaft $(G A B A d)$ ), but the synapse is not visible in this plane of section. Larger gold particles $(30 \mathrm{~nm})$ showing immunoreactivity for GABA are seen as larger black dots. Scale bar, $0.5 \mu \mathrm{m}$.

labeling for glutamate and GABA are shown in Figures 2-6 and 7 , respectively.

We made a number of additional measurements in an effort to provide more detailed information about similarities and differences between the synaptic arrangements made by K LGN axons and other local axons (e.g., axons from layer IV carrying indirect signals from the LGN M and P pathways). First, we evaluated the cross-sectional area of all labeled $\mathrm{K}$ axon terminals and postsynaptic dendritic shafts in which both presynaptic and postsynaptic profiles were distinct. $\mathrm{K}$ axon terminal and target sizes were compared with the sizes of all other local glutamatergic axonal profiles and their dendritic shaft targets. Only dendritic shafts that could be clearly identified as containing glutamate or GABA as a transmitter were included in the measurements. Table 2 shows that for all three primate species, $\mathrm{K}$ axon terminals were significantly larger in area (on average twice the size) when compared with the remaining local population of glutamatergic axon terminals. The size distribution of $\mathrm{K}$ axon terminals in comparison to the local population of glutamate containing axon terminals is shown in Figure 8.

Second, we compared the size of $\mathrm{K}$ axon terminals that made synapses with spines with those that made synapses with dendritic shafts containing either glutamate or GABA. Comparisons were made separately for each of the three primate species. No differences were found using an ANOVA ( $p=0.98$ for owl monkeys; $p=0.88$ for squirrel monkeys; $p=0.97$ for macaque monkeys).

A similar comparison was made between the sizes of GABAergic dendritic shafts receiving synapses from $\mathrm{K}$ axons and those 


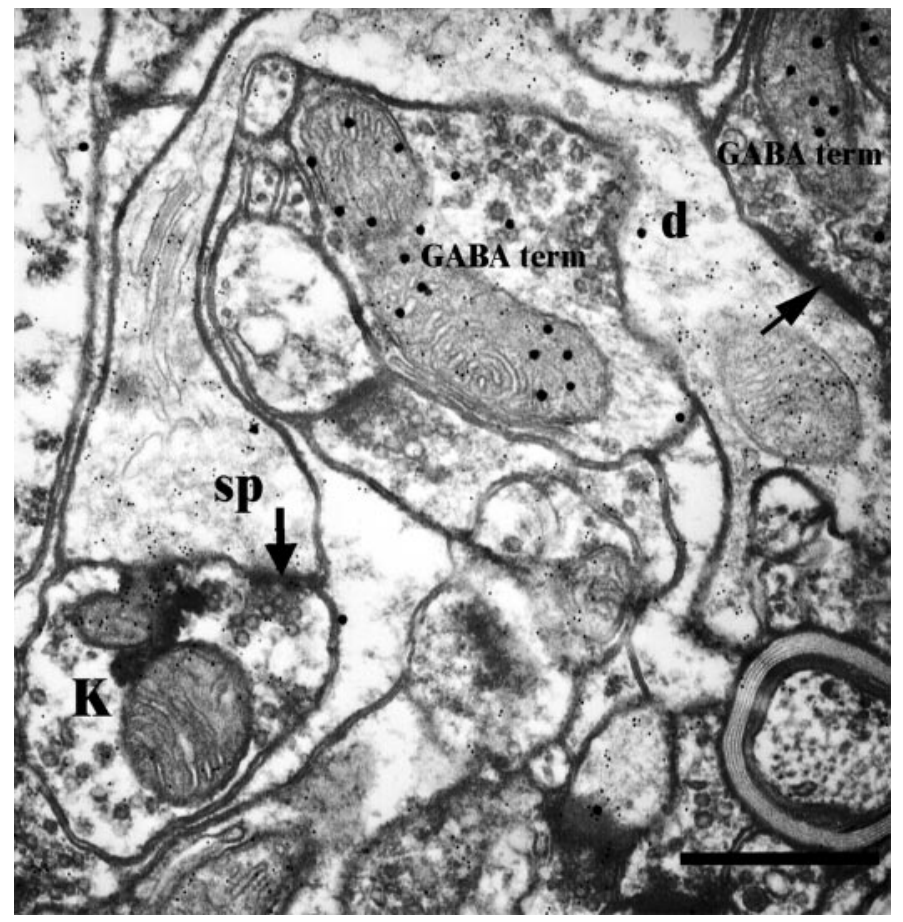

Figure 6. Squirrel monkey. A glutamatergic dendrite $(d)$ with spine $(s p)$ receives two synaptic contacts, one from a $\mathrm{K}$ axon (thick arrow) and another from a GABAergic terminal (GABA term; thin arrow). Black amorphous material indicates WGA-HRP electron-dense reaction product in the $\mathrm{K}$ axon $(K)$. Scale bar, $0.5 \mu \mathrm{m}$.

receiving input from other local glutamatergic axons. We found that in all three primate species, $\mathrm{K}$ axons tend to make contact with larger postsynaptic GABAergic dendritic shafts than do other local axons $\left(1.63 \pm 0.09 \mu \mathrm{m}^{2}, n=3\right.$ vs $0.82 \pm 0.07 \mu \mathrm{m}^{2}, n=$ 69 for owl monkeys; $2.24 \pm 0.63 \mu \mathrm{m}^{2}, n=9 \mathrm{vs} 1.65 \pm 0.19 \mu \mathrm{m}^{2}$, $n=12$ for squirrel monkeys; and $1.44 \pm 0.58 \mu \mathrm{m}^{2}, n=3 \mathrm{vs} 0.74 \pm$ $0.08 \mu \mathrm{m}^{2}, n=53$ for macaque monkeys for all local GABAergic dendritic shafts, respectively). Larger samples will be required to determine whether these differences are significant.

\section{Differences between species}

Two measures appeared to distinguish the diurnal monkeys (macaque and squirrel monkeys) from the nocturnal monkey (owl monkey). In the diurnal species a much larger percentage (38$40 \%$ ) of the total population of K axons terminated on glutamatergic dendritic shafts (as opposed to spines) than in the nocturnal owl monkey $(25 \%)$. In addition, as shown in Table 3 , when we compared the sizes of postsynaptic glutamatergic dendritic shafts contacted by $\mathrm{K}$ axons with the sizes of all glutamatergic dendritic shafts in the local area, we found that $\mathrm{K}$ axons in both diurnal primates terminate on relatively larger glutamatergic postsynaptic dendritic shafts than do $\mathrm{K}$ axons in the nocturnal owl monkeys.

In addition to differences that appeared to correlate with visual lifestyle (diurnal versus nocturnal), we found one species difference that correlated with evolutionary distance. In the New World simians, a small percentage of $\mathrm{K}$ axons makes multiple synaptic contacts. In owl monkeys $15.2 \%$ of K axons (7 of 46) and in squirrel monkeys $9.1 \%$ of $\mathrm{K}$ axons ( 6 of 66) make contacts with several postsynaptic targets: with one spine and one shaft (Fig. 7) or with more than one spine (Fig. 5). In contrast, none of the

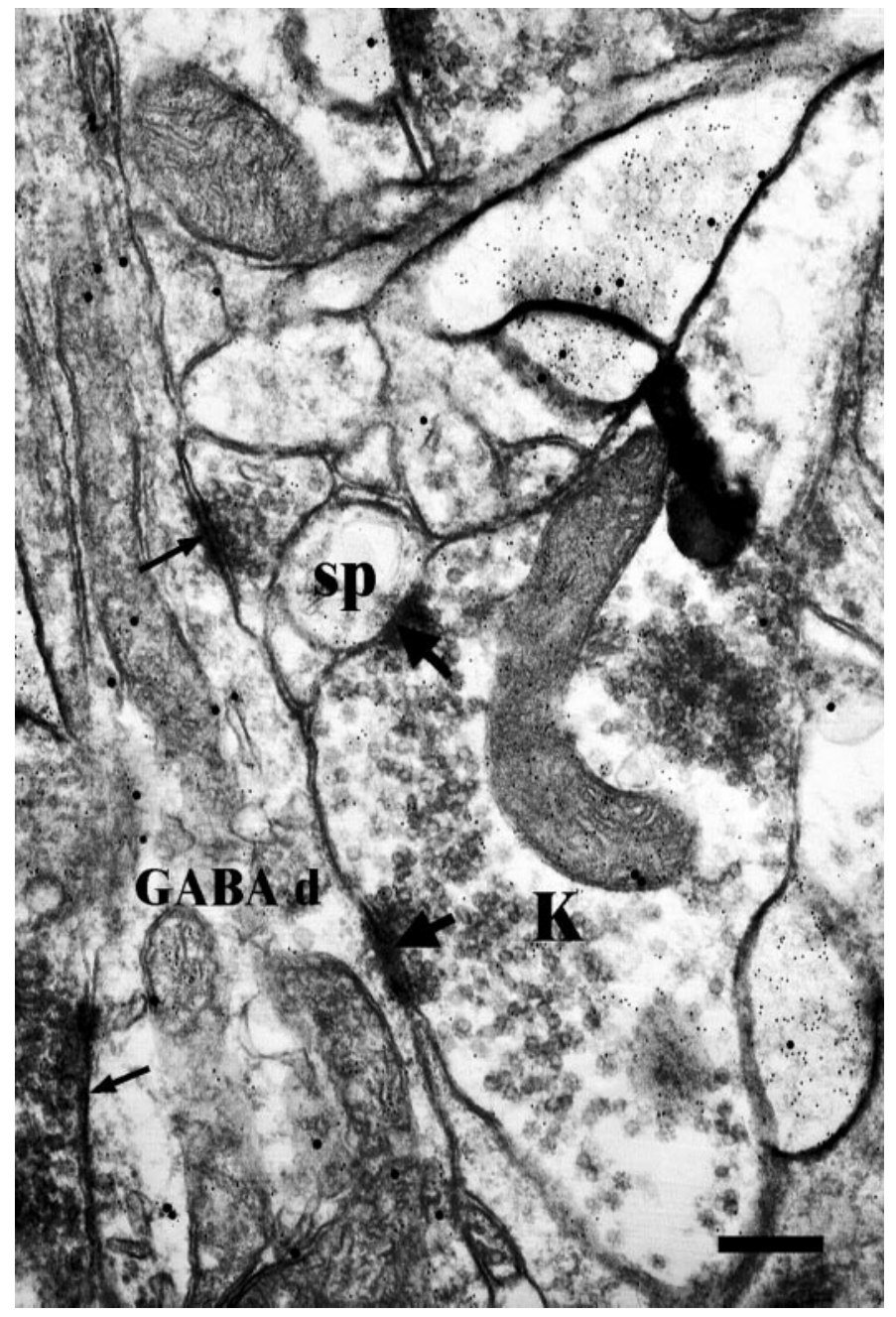

Figure 7. Squirrel monkey. Some K axons are involved in complex synaptic arrangements. This $\mathrm{K}$ axon $(K)$ synapses (indicated by a thick arrows) on both an inhibitory GABAergic dendritic shaft $(G A B A d)$ and a spine $(s p)$. Larger gold particles $(30 \mathrm{~nm})$ showing immunoreactivity for GABA are seen as larger black dots. Note that the same GABAergic dendritic shaft receives additional input from two other glutamatergic axon terminals (thin arrows). Black amorphous material indicates WGAHRP electron-dense reaction product in the K axon. Scale bar, $0.5 \mu \mathrm{m}$.

\section{Table 2. Sizes of axon terminals}

Species $\mathrm{K}$ terminals All glutamatergic terminals

Owl monkey

Squirrel monkey $1.39 \pm 0.12^{*}(n=46) \quad 0.70 \pm 0.04(n=137)$

Macaque monkey

$1.79 \pm 0.16^{*}(n=66)$

$0.95 \pm 0.10(n=54)$

All data are expressed in micrometers squared as means \pm SEM; *indicates that $\mathrm{K}$ axon terminals are significantly different from the remaining population of glutamatergic terminals $(t$ test; $p<0.05)$.

$53 \mathrm{~K}$ axons in macaque monkeys made multiple contacts with postsynaptic targets. These percentages, however, are likely to be an underestimate because serial reconstructions through the entire bouton were not performed.

A final species difference that did not correlate with either life style or evolutionary similarity was the finding that $\sim 50 \%$ of $\mathrm{K}$ axons in squirrel monkeys make perforated synaptic contacts with their targets versus $\sim 5-6 \%$ in owl and macaque monkeys. 


\section{Size distributions of axon terminals in CO-blobs}

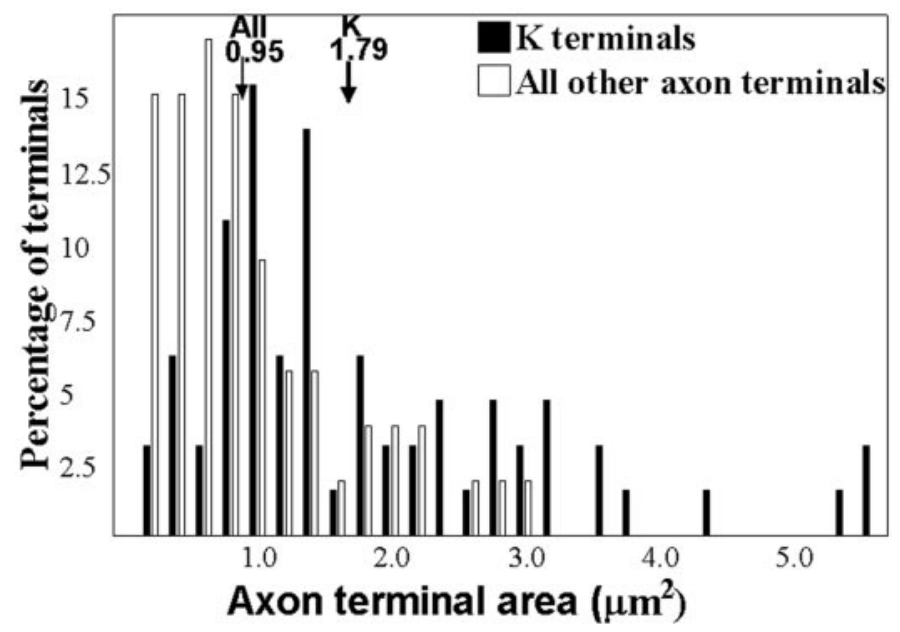

Figure 8. Squirrel monkey. K axon terminals (black bars) are on average larger in size than local axon terminals (white bars) in the local area of $\mathrm{CO}$ blobs. The arrows and the numbers above them show, respectively, the mean size of $\mathrm{K}$ axon terminals $\left(1.79 \pm 0.16 \mu \mathrm{m}^{2}\right)$ and the mean size of all local glutamatergic axon terminals $\left(0.95 \pm 0.10 \mu \mathrm{m}^{2}\right)$. See Results for details.

Table 3. Sizes of postsynaptic glutamatergic dendritic shafts

Postsynaptic to $\mathrm{K}$ axons-glutamatergic

Species dendritic shafts

All other glutamatergic

Owl monkey $0.75 \pm 0.08(n=11)$ dendritic shafts

Squirrel monkey

$1.73 \pm 0.32^{*}(n=21)$

$0.73 \pm 0.04(n=189)$

Macaque monkey

$1.21 \pm 0.18^{*}(n=18)$

$0.87 \pm 0.08(n=65)$

$0.51 \pm 0.03(n=276)$

All data are expressed in micrometers squared as means \pm SEM; *indicates that the means are significantly different from the remaining population of glutamatergic dendritic shafts $(t$ test; $p<0.05)$.

\section{DISCUSSION}

\section{Common features of K LGN circuits across primates}

Although $\mathrm{CO}$ blobs are recognized as a ubiquitous feature of primate $\mathrm{V} 1$, the role of the $\mathrm{CO}$ blobs in vision remains controversial. At one extreme are arguments that regions exhibiting dense $\mathrm{CO}$ staining are simply zones of thalamic input where the metabolism in cortex is slightly higher; $\mathrm{CO}$ blobs are the targets for $\mathrm{K}$ axons, just as layer IV (another CO-dense layer) is the target of $\mathrm{M}$ and $\mathrm{P}$ axons. At the other extreme is the proposal that $\mathrm{CO}$ blobs are artifacts of activity-dependent rules of development (Purves and LaMantia, 1990). The most popular proposal still remains that $\mathrm{CO}$ blobs reflect functional specialization for color in diurnal primates (Livingstone and Hubel, 1984; Ts'o and Gilbert, 1988). Support for a role in color also comes from published data on K LGN cells in marmosets (Martin et al., 1997; White et al., 1998) and preliminary data in macaque monkeys (Reid et al., 1997) suggesting that a percentage of K cells $(20 \%$ in marmosets) responds to signals from $\mathrm{S}$ cones (blue $\mathrm{ON}$ ); however, no LGN K cells have been identified that respond to red/green (i.e., $\mathrm{L}$ and $\mathrm{M}$ cones). Therefore, if $\mathrm{CO}$ blobs are part of a color channel, they must combine chromatic signals from $\mathrm{P}$ and $\mathrm{K}$ cells. If this is true, then we still need to understand what $\mathrm{CO}$ blobs are doing in nocturnal primates, such as owl monkeys, that do not express the $\mathrm{S}$ cone pigment gene (Jacobs et al., 1993) and are most likely color blind (Jacobs et al., 1996). Interestingly, in many respects (morphology and connectivity), the S cone (blue) system more closely resembles the rod system than the $\mathrm{L}$ and $\mathrm{M}$ cone channels in vision (Kolb et al., 1997). In fact, some evidence suggests that rods participate in the "blue" mechanism (Trezona, 1970) and signals from rods and S cones can interact (Naarendorp et al., 1996) and share the same pathway. Virsu and colleagues (1987) reported such sharing of signals from rods and S cones in macaque LGN, although this result remains controversial (Lee et al., 1997). If true, it could suggest a mechanism to explain why the $\mathrm{K}$ pathway is preserved in nocturnal primates. Perhaps the portion of the $\mathrm{K}$ pathway that is dominated by $\mathrm{S}$ cones in diurnal monkeys becomes part of a second rod-dominated pathway in nocturnal primates. This is in agreement with an older proposal that cells in the $\mathrm{CO}$ blobs are concerned, in general, with contrast (color or brightness) as opposed to cells in the interblobs that are more concerned with geometrical variables (Allman and Zucker, 1990; DeBruyn et al., 1993). This idea would also agree with our finding that the $\mathrm{K}$ pathway circuitry is quite similar across diurnal and nocturnal primates. Thus, under nocturnal conditions the $\mathrm{K}$ $\mathrm{CO}$ blob pathway may simply switch in nocturnal primates to a rod pathway.

In fact, the similarities in the $\mathrm{K}$ pathway far outweigh the differences, suggesting that there has not been a major change in the $\mathrm{K}$ pathway circuitry within the $\mathrm{CO}$ blobs that correlates with the shift from color vision to lack of color vision and that the common structural elements of the $\mathrm{K}$ pathway across primates reflect some function that they share or that all LGN input pathways share. The similarities that we see between $\mathrm{K}$ axon populations include the demonstration that $\mathrm{K}$ axons are (1) glutamatergic, (2) make asymmetric (Gray's type I) synapses mainly with spines, and (3) engage in simple synaptic arrangements with glutamatergic postsynaptic targets typically involving single synaptic contacts. The tendency for $\mathrm{K}$ geniculocortical axons to contact predominantly spines of excitatory cells extends also to both cat $\mathrm{X}$ and $\mathrm{Y}$ geniculocortical boutons in area 17 and cat $\mathrm{Y}$ axons in area 18, and $\mathrm{M}$ and $\mathrm{P}$ axons in layer IV of primates (Garey and Powell, 1971; Tigges and Tigges, 1979; Winfield et al., 1982; Winfield and Powell, 1983; Freund et al., 1989; Ding and Casagrande, 1998), as well as to rat geniculocortical axons in area 17 (Garey and Powell, 1971; LeVay and Gilbert, 1976; Winfield and Powell, 1976, 1983; Peters and Feldman, 1977; Freund et al., 1985, Kharazia and Weinberg, 1994), suggesting that these are general features of all geniculocortical axons in mammals.

In addition to spines and dendritic shafts containing glutamate, a minority (5-15\%) of $\mathrm{K}$ axons in all three species makes synapses with the dendritic shafts of inhibitory (GABAergic) interneurons. This percentage of contacts with inhibitory interneurons is similar to that of the local population of axons, suggesting that $\mathrm{K}$ axons do not relate in unique ways to the GABAergic circuitry, with the exception that $\mathrm{K}$ axons tend to contact larger GABAergic dendrites than the local population of axons (see also below). Approximately 15-20\% of all cortical neurons are GABAergic (Fitzpatrick et al., 1987; Hendry et al., 1987), and the proportion of GABAergic dendrites reported in the $\mathrm{CO}$ blob neuropil of macaque monkeys is similar (Beaulieu et al., 1992; Nie and Wong-Riley 1995).

\section{Comparison among $\mathrm{K}, \mathrm{M}$, and $\mathbf{P}$ LGN synaptic circuits}

The CO blobs in layer IIIB receive numerous intrinsic and a greater variety of extrinsic connections than have been reported in layer IV. In addition to axons from cells in both IV $\alpha$ and IV $\beta$ layers (the $\mathrm{M}$ and $\mathrm{P}$ recipient sublayers), $\mathrm{CO}$ blobs receive input 
from cells in all cortical layers except layer I, as well as input from local cells (Lund and Yoshioka, 1991; Peters and Sethares, 1991; Casagrande et al., 1992; Lachica et al., 1992, 1993; Boyd et al., 2000). Extrinsic connections of the CO blobs include not only the LGN K pathway, but also input from a number of extrastriate visual areas (e.g., feedback from V2), as well as input from the pulvinar (Kaas and Huerta, 1988; Desimone et al., 1990). Within the CO blobs there are no spiny stellate cells (Lund, 1984). Therefore, in the CO blobs, all dendritic spines arise from either local pyramidal cells or pyramidal cells from other layers, especially layer V (Peters and Sethares, 1991). These relationships indicate that $\mathrm{K}$ axons could have direct access to output neurons, unlike the axons of $\mathrm{M}$ and $\mathrm{P}$ cells, which terminate exclusively on spiny stellate cells in layer IV and avoid pyramidal dendrites (Lund, 1984). Our quantitative comparison reveals that K axon terminals are larger in area than local glutamatergic axon terminals. This suggests that $\mathrm{K}$ axons have a greater impact on V1 output neurons, unless the terminals arriving from layer IV (reflecting the indirect inputs from the $\mathrm{P}$ and $\mathrm{M}$ pathways) are skewed in size away from the local mean. Although the proportion of GABAergic target elements contacted by the K pathway $(5-15 \%)$ is similar to that described in the literature for $\mathrm{M}$ and $\mathrm{P}$ cells (5-10\%) (Freund et al., 1989), it is intriguing that $\mathrm{K}$ axons in all three monkey species contact significantly larger postsynaptic GABAergic dendritic shafts than do local axons, suggesting that $\mathrm{K}$ axons terminate closer to the cell bodies of these inhibitory cells than axons carrying $\mathrm{M}$ and $\mathrm{P}$ signals from layer IV.

Taken together, these comparisons among the synaptic relationships of $\mathrm{K}, \mathrm{M}$, and $\mathrm{P}$ axons suggest that all three parallel LGN streams use similar strategies at the first stage of information transfer to cortical circuits, but that the $\mathrm{K}$ pathway has a stronger than suspected impact on messages outgoing from V1 given the location and size of its axons. Additionally, the $\mathrm{K}$ pathway appears to be in a position to more efficiently activate inhibitory neurons. This could allow signals arriving from $\mathrm{K}$ axons to be more rapidly shut down in comparison to signals arriving via $\mathrm{M}$ and $\mathrm{P}$ axons, at least according to models that propose feedforward inhibition of incoming LGN afferent signals (Somogyi, 1989; Berman et al., 1991, 1992; Douglas and Martin, 1991).

\section{Differences in K LGN circuits across primates}

Despite the many across-species similarities in $\mathrm{K}$ pathway organization, there are intriguing differences. The most interesting of these differences are those that could correlate with the presence or absence of color vision. Comparison of the diurnal monkeys (macaque and squirrel monkeys) that have color vision with a nocturnal owl monkey that lacks color vision showed that a greater proportion of $\mathrm{K}$ axons in the diurnal monkeys synapse with dendritic shafts (as opposed to spines) as well as with larger glutamatergic dendritic shafts. This shift could reflect a loss of one population of $\mathrm{K}$ axons in owl monkeys, a population conveying information from the missing $\mathrm{S}$ cone pathway (Jacobs et al., 1996). This change also fits with data in marmosets showing that only a small proportion of K axons $(20 \%)$ actually carry color signals (i.e., S cone signals); the remainder do something else (Martin et al., 1997; White et al., 1998). Such a scenario would also fit the proposed evolutionary history of the owl monkey, suggesting that the ancestors of owl monkeys had $\mathrm{S}$ cones (and likely color vision) and that they only recently lost $\mathrm{S}$ cones under some pressure to become nocturnal (Martin, 1990). Another conclusion that could be drawn from these data is that the $\mathrm{K}$ pathway input to $\mathrm{CO}$ blob glutamatergic dendrites in diurnal primates occurs at sites that can exert relatively greater dominance compared with other afferents, and that this distinctive feature of the K pathway has been minimized in the nocturnal owl monkey, perhaps as a consequence to the loss of color vision. In that case the prediction would be that other diurnal primates with $\mathrm{S}$ cones (e.g., marmosets) should show the pattern that we have found in the macaque and squirrel monkeys, whereas other nocturnal primates that lack $\mathrm{S}$ cones (e.g., bush babies) should show the pattern seen in the owl monkey. Nevertheless, these diurnal/ nocturnal differences account for only a small percentage of the $\mathrm{K}$ axons in these three species $(\sim 20 \%)$. These findings support the conclusion that most of the signals that the $\mathrm{K}$ pathway conveys to the $\mathrm{CO}$ blobs are concerned with something other than color.

\section{REFERENCES}

Allman J, Zucker S (1990) Cytochrome oxidase and functional coding in primate striate cortex: a hypothesis. Cold Spring Harb Symp Quant Biol 55:979-982.

Beaulieu C, Kisvarday Z, Somogyi P, Cynader M, Cowey A (1992) Quantitative distribution of GABA-immunopositive and -immunonegative neurons and synapses in the monkey striate cortex (area 17). Cereb Cortex 2:295-309.

Berman NJ, Douglas RJ, Martin KA, Whitteridge D (1991) Mechanisms of inhibition in cat visual cortex. J Physiol (Lond) 440:697-722.

Berman NJ, Douglas RJ, Martin KA (1992) GABA-mediated inhibition in the neural networks of visual cortex. Prog Brain Res 90:443-476.

Boyd JD, Mavity-Hudson JA, Casagrande VA (2000) The connections of layer 4 subdivisions in the primary visual cortex (V1) of the owl monkey. Cereb Cortex 10:644-662.

Calkins DJ, Sterling P (1999) Evidence that circuits for spatial and color vision segregate at the first retinal synapse. Neuron 24:313-321.

Casagrande VA (1994) A third parallel visual pathway to primate area V1. Trends Neurosci 17:305-310.

Casagrande VA (1999) The mystery of the visual system K pathway. J Physiol (Lond) 517:630.

Casagrande VA, Kaas JH (1994) The afferent, intrinsic, and efferent connections of primary visual cortex in primates. In: Cerebral cortex, Vol. 10, primary visual cortex of primates (Peters A, Rockland K, eds), pp 201-259. New York: Plenum.

Casagrande VA, Mavity-Hudson JA, Taylor JG (1992) Intrinsic connections of owl monkey striate cortex: difference between cytochrome oxidase (CO) blobs and interblobs. Soc Neurosci Abstr 18:389.

Casagrande VA, Ding Y, Boyd JD (1997) The morphology of LGN axons from different K layers in V1 of macaque monkey. Soc Neurosci Abstr 23:2361.

Condo GJ, Casagrande VA (1990) Organization of cytochrome oxidase staining in the visual cortex of nocturnal primates (Galago crassicaudatus and Galago senegalensis): I. Adult patterns. J Comp Neurol 293:632-645.

DeBruyn EJ, Casagrande VA, Beck PD, Bonds AB (1993) Visual resolution and sensitivity of single cells in the primary visual cortex (V1) of a nocturnal primate (bush baby): correlations with cortical layers and cytochrome oxidase patterns. J Neurophysiol 69:3-18.

Desimone R, Wessinger M, Thomas L, Schneider W (1990) Attentional control of visual perception: cortical and subcortical mechanisms. Cold Spring Harb Symp Quant Biol 55:963-971.

Ding Y, Casagrande VA (1995) The morphology of LGN axons that terminate in the CO blobs and primate VI. Soc Neurosci Abstr 21:394.

Ding Y, Casagrande VA (1997) The distribution and morphology of LGN K pathway axons within the layers and CO blobs of owl monkey V1. Vis Neurosci 14:691-704.

Ding Y, Casagrande VA (1998) Synaptic and neurochemical characterization of parallel pathways to the cytochrome oxidase blobs of primate visual cortex. J Comp Neurol 391:429-443.

Douglas RJ, Martin KA (1991) A functional microcircuit for cat visual cortex. J Physiol (Lond) 440:735-769.

Fitzpatrick D, Itoh K, Diamond IT (1983) The laminar organization of the lateral geniculate body and the striate cortex in the squirrel monkey (Saimiri sciureus). J Neurosci 3:673-702.

Fitzpatrick D, Lund JS, Schmechel DE, Towles AC (1987) Distribution of GABAergic neurons and axon terminals in the macaque striate cortex. J Comp Neurol 264:73-91.

Freund TF, Martin KA, Somogyi P, Whitteridge D (1985) Innervation of cat visual areas 17 and 18 by physiologically identified X- and Y-type thalamic afferents. II. Identification of postsynaptic targets by GABA immunocytochemistry and Golgi impregnation. J Comp Neurol 242:275-291.

Freund TF, Martin KAC, Soltesz I, Somogyi P, Whitteridge D (1989) Arborization pattern and postsynaptic targets of physiologically iden- 
tified thalamocortical afferents in striate cortex of the macaque monkey. J Comp Neurol 289:315-336.

Garey LJ, Powell TPS (1971) An experimental study of the termination of the lateral geniculo-cortical pathway in the cat and monkey. Proc R Soc Lond B Biol Sci 179:41-63.

Hendry SH, Reid C (2000) The koniocellular pathway in primate vision. Annu Rev Neurosci 23:127-153.

Hendry SH, Schwark HD, Jones EG, Yan J (1987) Numbers and proportions of GABA-immunoreactive neurons in different areas of monkey cerebral cortex. J Neurosci 7:1503-1519.

Horn AKE, Hoffman KP (1987) Combined GABA-immunocytochemistry and TMB-HRP histochemistry of pretectal nuclei projecting to the inferior olive in rats, cats and monkeys. Brain Res 409:133-138.

Jacobs GH, Deegan JF, Neitz J, Crognale MA, Neitz M (1993) Photopigments and color vision in the nocturnal monkey, Aotus. Vision Res 33:773-783.

Jacobs GH, Neitz M, Neitz J (1996) Mutations in S-cone pigment genes and the absence of colour vision in two species of nocturnal primate. Proc R Soc Lond B Biol Sci 263:705-710.

Kaas JH, Huerta MF (1988) Subcortical visual system of primates. In: Comparative primate biology, Vol 4 (Steklis HP, ed), pp 327-391. New York: Wiley.

Kharazia VN, Weinberg RJ (1994) Glutamate in thalamic fibers terminating in layer IV of primary sensory cortex. J Neurosci 14:6021-6032.

Kolb H, Goede P, Roberts S, McDermott E, Gouras P (1997) Uniqueness of the S-cone pedicle in the human retina and consequences for color processing. J Comp Neurol 386:443-460.

Lachica EA, Casagrande VA (1992) Direct W-like geniculate projections to the cytochrome oxidase $(\mathrm{CO})$ blobs in primate visual cortex: axon morphology. J Comp Neurol 319:141-158.

Lachica EA, Beck PD, Casagrande VA (1992) Parallel pathways in macaque monkey striate cortex: anatomically defined columns in layer III. Proc Natl Acad Sci USA 89:3566-3570.

Lachica EA, Beck PD, Casagrande VA (1993) Intrinsic connections of layer III of striate cortex in squirrel monkey and bush baby: correlations with patterns of cytochrome oxidase. J Comp Neurol 329:163-187.

Lee BB, Smith VC, Pokorny J, Kremers J (1997) Rod inputs to macaque ganglion cells. Vision Res 37:2813-2828.

Lennie P, Krauskopf J, Sclar G (1990) Chromatic mechanisms in striate cortex of macaque. J Neurosci 10:649-669.

LeVay S, Gilbert CD (1976) Laminar patterns of geniculocortical projection in the cat. Brain Res 113:1-19.

Livingstone MS, Hubel DH (1982) Thalamic inputs to cytochrome oxidase rich regions in monkey visual cortex. Proc Natl Acad Sci USA 79:6098-6101.

Livingstone MS, Hubel DH (1984) Anatomy and physiology of a color system in the primate visual cortex. J Neurosci 4:309-356.

Lund JS (1984) Spiny stellate cells. In: Cerebral cortex, Vol 1, cellular components of the cerebral cortex (Peter A, Jones EG, eds), pp 255308. New York: Plenum.

Lund JS, Yoshioka T (1991) Local circuit neurons of macaque monkey striate cortex: III. Neurons of laminae 4B, 4A and 3B. J Comp Neurol 311:234-258

Martin PR, White AJR, Goodchild AK, Wilder HD, Sefton AE (1997) Evidence that blue-on cells are part of the third geniculocortical pathway in primates. Eur J Neurosci 9:1536-1541.

Martin RD (1990) Primate origins and evolution. Princeton: Princeton UP.

Mesulam MM (1978) Tetramethyl benzidine for horseradish peroxidase neurohistochemistry: a non-carcinogenic blue reaction product with superior sensitivity for visualizing neural afferents and efferents. J Histochem Cytochem 26:106-117.
Naarendorp F, Rice KS, Sieving PA (1996) Summation of rod and S cone signal at threshold in human observers. Vision Res 36:2681-2688.

Nie F, Wong-Riley MT (1995) Double labeling of GABA and cytochrome oxidase in the macaque visual cortex: quantitative EM analysis. J Comp Neurol 356:115-131.

Nieto-Sampedro M, Hoff SF, Cotman CW (1982) Perforated postsynaptic densities: probable intermediates in synapse turnover. Proc Natl Acad Sci USA 79:5718-5722.

Peters A, Feldman ML (1977) The projection of the lateral geniculate nucleus to area 17 of the rat cerebral cortex. IV. Terminations on spiny dendrites. J Neurocytol 6:669-689.

Peters A, Sethares C (1991) Organization of pyramidal neurons in area 17 of monkey visual cortex. J Comp Neurol 306:1-23.

Phend KD, Weinberg RJ, Rustioni A (1992) Techniques to optimize post-embedding single and double staining for amino acid neurotransmitters. J Histochem Cytochem 40:1011-1020.

Pierce JP, Mendell LM (1993) Quantitative ultrastructure of la boutons in the ventral horn: scaling and positional relationships. J Neurosci 13:4748-4763.

Purves D, LaMantia AS (1990) Numbers of "blobs" in the primary visual cortex of neonatal and adult monkeys. Proc Natl Acad Sci USA 87:5764-5767.

Reid RC, Alonso JM, Hendry SHC (1997) S-cone input is relayed to visual cortex from two koniocellular layers of macaque LGN. Soc Neurosci Abstr 23:13.

Reynolds ES (1963) The use of lead citrate at high $\mathrm{pH}$ as an electron opaque stain in electron microscopy. J Cell Biol 17:208-212.

Somogyi P (1989) Synaptic organization of GABAergic neurons and $\mathrm{GABA}_{\mathrm{A}}$ receptors in the lateral geniculate nucleus and visual cortex. In: Neural mechanisms of visual perception (Lam DKT, Gilbert CD eds), pp 35-62. Houston: Portfolio Publishing.

Thompson AL, Bogen JE, Marsh JF (1979) Cultural hemisphericity: evidence from cognitive tests. Int J Neurosci 9:37-43.

Tigges M, Tigges J (1979) Types of degenerating geniculocortical axon terminals and their contribution to layer IV of area 17 in the squirrel monkey (Saimiri). Cell Tissue Res 196:471-486.

Trezona PW (1970) Rod participation in the blue mechanism and its effect on colour matching. Vision Res 10:317-332.

Ts'o DY, Gilbet CD (1988) The organization of chromatic and spatial interactions in the primate striate cortex. J Neurosci 8:1712-1727.

Virsu V, Lee BB, Creutzfeldt OD (1987) Mesopic spectral responses and the Purkinje shift of macaque lateral geniculate nucleus cells. Vision Res 27:191-200.

White AJ, Wilder HD, Goodchild AK, Sefton AJ, Martin PR (1998) Segregation of receptive field properties in the lateral geniculate nucleus of a New-World monkey, the marmoset Callithrix jacchus. J Neurophysiol 80:2063-2076.

Wikler KC, Rakic P (1990) Distribution of photoreceptor subtypes in the retina of diurnal and nocturnal primates. J Neurosci 10:3390-3401.

Winfield DA, Powell TP (1976) The termination of thalamo-cortical fibres in the visual cortex of the cat. J Neurocytol 5:269-281.

Winfield DA, Powell TP (1983) Laminar cell counts and geniculocortical boutons in area 17 of cat and monkey. Brain Res 277:223-229.

Winfield DA, Rivera-Dominguez M, Powell TP (1982) The termination of geniculocortical fibers in area 17 of the visual cortex in the macaque monkey. Brain Res 231:19-32.

Xu X, Ichida JM, Allison JD, Boyd JD, Bonds AB, Casagrande VA (2001) A comparison of koniocellular (K), magnocellular (M), and parvocellular $(\mathrm{P})$ receptive field properties in the lateral geniculate nucleus (LGN) of the owl monkey (Aotus trivirgatus). J Physiol (Lond) 531:203-218. 